\title{
Anonymous or Confidentiality in Opinion Survey? (The Selective Aproach for Sampling in Surveys where are Included Delicate Questions)
}

\author{
Hysamedin Feraj \\ PhD., Faculty of Sociale Sciences, Tirana University \\ hferaj@gmail.com \\ Aleksandër Kocani \\ Prof.As.PhD., Faculty of Sociale Sciences, \\ Tirana University, Albania
}

\section{Doi:10.5901/mjss.2013.v4n2p593}

\begin{abstract}
:
Who consults research methods books can easily make evidence of the stress for the need to insure the respondents anonymous in surveys where are used questions considered as delicate one. Generally is given the recommendation to avoid the delicate questions for gathering trustworthy data and in the case of impossibility to avoid them at least to insure the response confidentiality. In case of impossibility to avoid such a questions it is recommended to do the maximal efforts to guaranty the respondents' anonymous or at least their reponses' confidentiality. Both two alternatives are suggested especially for the studies where the use of delicate questions is part of study and it is impossible to avoid it. Here by our opinion the problem is if it is always valuable the alternative suggestion about the giving of guaranty for the respecting the respondents' reponse confidentiality on absence of possibility to insure their anonymous.
\end{abstract}

Anyone who consults research methods books can easily make evidence of the stress for the need to insure the respondents anonymous in surveys where are used questions considered as delicate one. Generally is given the recommendation to avoid the delicate questions for gathering trus tworthy data and in the case of impossibility to avoid them at least to insure the response confidentiality ${ }^{1}$. Here you are some problems. Firtsly the considering as delicate for any qyestion isn't an universal choice but it depends on the society type, on political culture level and social emancipation. So in democratic developed countries such a thing as questioning about respondent's voting behavior and their political preferencies are not be percepted as delicate ones by the body of voters and social researchers. And this is conditioned by the fact that in these countries the expression freedom is not only a juridical reality but also a practical one. There are institutions which protect with « jealousy » such a freedom for their citizens. And now you can easily understand why they think and feel themselves as not in danger where are publically expressing their political or electorate preferences. There are not reasons for them to be suspicious when are responding to questions concerning their political preferences. So their answers for such a questions dont « suffer » of data non realibility (or absence of sincerity). This is not the case for the countries in democracy reconstructing, such as The Albanian Republic. In these countries, of course there are lows which formally (but not really) protect the expression freedom. But there are some problems concernig the low implementation here including the low which protect the expresssion freedom. The institutions are relatively not strong and do not practically guaranty anyone to be untouched if his political and electorate preferences will be identified. It is for this reason that any voter in these countries can be feared concerning the possibility to be identified, when is responding to question percepted by him as delicate. So you naturally may expect as defendmechanism the using of refutation to be interviewed or the giving of non sincere responses. The first reaction increases the scale of non implementation of drowed sampling. While the second reaction increases in a indeterminated

${ }^{1}$ Bernstein, Robert A., Dyer, Janes A.. An introduction to Political Science Methods, Prentice Hall Englewood Cliffs: New Jersy, p. 93-94 
way the measure error and so decreasing the data reliability. Both reactions are unpleased and it would be better to avoid them.

Of course firstly you may think to avoid the questions percepted by the respondents as delicates. In case of impossibility to avoid such a questions it is recommended to do the maximal efforts to guaranty the respondents' anonymous or at least their reponses' confidentiality. Both two alternatives are suggested especially for the studies where the use of delicate questions is part of the study and it is impossible to avoid it. Here by our opinion the problem is if it isalwaysvaluable the alternative suggestion about the giving of guaranty for the respecting the respondents' reponse confidentiality on absence of possibility to insure their anonymous.

Such a suggestion suposes a respondents' reliabel comportation towards the loyalty of promise given by the interviewer. I.e., based on the belive the interviewer will take it promise for guaranty of reponses' confidentiality to delicate questions. In another hand, this means a relatively low level for the social diffidence parameter, which is not true for any society. In other words, it is needed that in mentioned society the most of voters think that it is possible to trust on unknown others. In our case the point is to trust or not to persons who make interview and are not known by the respondents. More concretely it is need to know how is the level of diffidence towards « others ».

The measures carried out by the researchers at Political Sciences Department, Tirana University since 1998 (more than 25 surveys extended during the years 1998, 2001, 2003, 2005, 2007, 2008, 2009, 2010, 2011 and 2012) show generally a level of diffidence varys from closely $80 \%$ to $90 \%$. Only in 2009 there was a lower level at $61 \%$. So such a level measured on the end of October 2012 is nearly $95 \%$.

With such a diffidence level it is not the question for the respondents to trust the interviewers' promise that anything their say «will strongly be confident». So if you want to have the survey data as reliable as possibledon'tbelieve to response confidentiality' formula. If you contact the respondents following a probabilistic sample schema which lets them the possibility to percept themselves as to be identifiable (by the name, home and job 's addresse), then there is no place to speak of their anonymous protection for. The only thing you may promise to respondents now is to insure them concerning their responses confidentiality.

But as we mentioned such a promise don't be considered as reliable in a society with high diffidence level. So you have to drown a sample which really allow to insure the respondents' anonymous. I.e., which allow to respondents to percept themselves as not recognizable and this way releasing them from the fear of being injured if they give sincere responses to questions considered as delicate ones. This is possible if you use in the last chain of a sample schema the quota method (by group age and gender).

Our survey experience since 1998 show that using quota in the last chain of a sample schema allow to really insure the respondents' non identifiability and so also the sincerity of their responses. In this way it is possible to gather by measure mentreliable data and to carried out relatively reliable conclusions which is the main aim for every scientific research.

\section{Bibliography}

Bernstein, Robert A., Dyer, Janes A., (1992), An introduction to Political Science Methods, Prentice Hall Englewood Cliffs: New Jersy.

Inglehart, R., Globalisation and postmodern values, The Washington Quaterly 23.1 (2000).

Inglehart, R., Baker, W. E., Modernization, Cultural Change, and the Persistence of Traditional Values American Sociological Review, 2000, Vol.65 (February).

Kocani, A., Percaktimi i marzhit të gabimit që fut kuota në hallkën e fundit të kampionimit të një anketimi kundrejt kampionimit sistematik, AKTET Revistë shkencore e Institutit Alb-shkenca, Vol IV, Nr.4, 2011. [The determination of the error margin introduced by quota in the last chain of a survey sample towards a systematic sample, The ACTS Scientific Review of Alb-science Institute, Vol IV, N4, 2011] ISSN 2073-2244. 